\title{
APROXIMACIÓN TRANSCULTURAL EN LA DIDÁCTICA DE LAS LENGUAS-CULTURAS: ¿UN PROCESO DISCUTIBLE O QUE MERECE SER DISCUTIDO?
}

\section{Chantal Forestal*}

RESUMEN: Este artículo es una toma de posición contra una de las tendencias actuales de la sociedad: "la tentación relativista", que encontramos en la didáctica de las lenguas y que, muy a menudo, se apoya sobre un principio de neutralidad. ¿El "componente transcultural" que concierne a la problemática de los valores universales es discutible, poco fiable y debe ser apartado de la discusión, o bien, merece ser discutido, especialmente en su relación con los otros componentes metaculturales, interculturales, multiculturales o co-culturales, particularmente en sus referencias a lo político y a la ética?

$$
\text { sose }
$$

ABSTRACT: This article takes a stance against a current societal trend: "the relative temptation," found in language teaching and frequently supported by a principle of neutrality. Is the transcultural component (which concerns the problem of universal values) questionable, disputed, unreliable, and something to be left out of the discussion or is it worth discussing, particularly in its relationship with the other components, namely meta-cultural, intercultural, multicultural or co-cultural, especially in their references to politics and to ethics?

PALABRAS CLAVE: Trans, relativismo cultural, universalismo, transcultural, didáctica, ética. KEYWORDS: Trans, cultural relativism, universalism, transcultural, teaching, ethics.

RECEPCIÓN: 7 de enero de 2010.

APROBACIÓN: 27 de enero de 2010.

* Catedrática, HDR, Université de Provence. 
CITAM Derechos Reservados.

La reproducción total o parcial de este artículo se podrá hacer si el ITAM otorga la autorización previamente por escrito. 


\section{APROXIMACIÓN TRANSCULTURAL EN LA DIDÁCTICA DE LAS LENGUAS-CULTURAS: ¿UN PROCESO DISCUTIBLE O QUE MERECE SER DISCUTIDO?*}

Un preámbulo: estar a favor de un proceso transcultural necesariamente implica referirse a la ética. En cierta forma, es estar de acuerdo con nuestro sector, con lo que decía Chirac cuando anunciaba que "el siglo XXI será el siglo de la ética o no será", retomando la célebre fórmula atribuida a Malraux, quien había dicho: "el siglo XXI será espiritual o no será". Sin embargo, nos podemos preocupar puesto que, mientras un hombre político habla más de moral o de ética, menos la aplica. Espero que mi propósito no caiga en esta contridicción.

\section{Elementos de reflexión a partir de la etimología del prefijo "trans"}

Prefijo tomado en préstamo del latín "trans"

Puede significar "a través" ("transeuropeo", que atraviesa Europa) o "al otro lado de" ("transalpino", al otro lado de una frontera). Evoca el pasaje, el intercambio, considerado ya sea positivamente, ya negativamente, o de manera alternativa uno o el otro. De esta manera, la transfusión sanguínea en el siglo XVII sugiere un intercambio posible de cualidades entre los vivos. En Francia, en la Liberación, los bancos de sangre eran vistos como depósitos de redistribución de un bien social

* Traducción de Maiala Meza, con la colaboración de Julián Meza. 
común; la transfusión aún más positiva se convierte en un elemento de solidaridad. De manera opuesta, puede ser considerada como francamente negativa en la transmisión de enfermedades (el escándalo de la sangre contaminada). Igualmente, conocemos las cuestiones médicas y bioéticas que plantea el "transexualismo". Éste puede ser la certidumbre negativa de no estar a gusto con el cuerpo, y más cuando se es el objeto en tanto que comunidad transfóbica (como es a menudo el caso de Francia, por ejemplo). Pero también puede ser la certidumbre positiva de tener la libertad de cambiar el ideal del yo.

\section{En el dominio cultural}

Lo "transcultural" pude significar la travesía de una cultura a otra, ya sea en el espacio o en el tiempo: de la cultura rural a la cultura urbana; de la cultura obrera a la cultura burguesa; de la cultura del Sur a la del Norte; de la cultura antigua (latina o griega) a la cultura moderna. En etnología, la "transculturación" concierne el proceso de transición de una cultura a otra, la cual participa de una transformación de la cultura tradicional y se lleva a cabo en el desarrollo de la cultura nueva. En didáctica de las lenguas, puede ser el reconocimiento de la multiplicidad intercultural de las posibilidades de las relaciones, los intercambios, de comprensión entre culturas-lenguas diferentes. Existe entonces la posibilidad de estar a gusto en la globalización (volverse multilingüe, cosmopolita, hombre planetario). Sin embargo, los fenómenos de aculturación (adaptación de un individuo al medio socio-cultural en el cual vive) pueden conllevar traumatismos de aculturación de los inmigrantes, unas veces considerados como "bien aculturados", otras como "mal aculturados" según su grado de dominio de la lengua francesa. Nos acordamos de lo que se podría calificar como ingerencia totalitaria, el informe Bénisti, que consideraba a la vez la estupidez y la violencia institucional, atentando contra los derechos humanos puesto que prohibía a los padres hablar en casa otro idioma que no fuera el francés. Como lo subraya el sociolingüista Louis-Jean Calvet con respecto a la exclusión de las minorías, para tranquilizar a los niños inmigrantes en el sistema escolar francés, habría que confortarlos en el idioma de sus padres. En efecto, si uno está 
orgulloso de su cultura de origen, es más fácil “integrar” la cultura del país de acogida, o mejor aún, asociarse (palabra prestada al vocabulario francés en 1789-93). El trabajador social o el pedagogo deben considerar esta tensión permanente de las dos culturas, tensión que no está libre de consecuencias sobre el plano psíquico, pero que deliberadamente trabajada por los sujetos puede crear en ellos una tercera cultura. Los temas cosmopolita y multilinguismo hoy en día están de moda. De esta manera, la prensa anglosajona ha sostenido la idea de que la cultura francesa estaría en claro retroceso porque está demasiado replegada sobre sí misma. ¿Se trata sólo de una "falta de porosidad" de la lengua-cultura francesa, de una falta de apertura, de una adaptación a la comunicación transnacional y transcultural, o se trata más bien de un problema de difusión debido a los límites actuales de la traducción del francés a otras lenguas? ¿Desde entonces no hay un problema de otro orden, a saber, la dominación económica anglosajona? No habría que olvidar que los intereses económicos y tecnológicos están, a partir de ahora, en el corazón de la cultura y, en consecuencia, parecen gobernar una cierta concepción de la transculturalidad. De esta manera, el Louvre se ha convertido en una verdadera multinacional que debe saber venderse para exportarse. ¿A qué precio? ¿El de la autocensura concerniente a ciertas obras juzgadas más o menos escandalosas? En este campo podemos anticipar futuros conflictos. (Ejemplo de Abu Dhabi: es un proyecto complejo con un riesgo de mercantilización, pero también de colonización: la cultura debe salir de su torre de marfil... ¿pero hasta qué punto?)

Hoy en día, lo transcultural parece estar representado principalmente por un medio, el medio televisivo. Éste es, muy a menudo, desconsiderado, puesto que es el responsable del dispersamiento, la diseminación de la cultura. Sin embargo, ¿podría una forma de arte basarse en la unidad plural de la cultura que, sin uniformizarse, reuniría y daría sentido y forma a elementos heterogéneos provenientes de las culturas "cultivadas", "populares" e incluso "comerciales" (véase el programa de France-culture "Le mauvais genre")? Sin embargo, durante mucho tiempo -y en

${ }^{1}$ Programa de radio que pone de manifiesto géneros artísticos considerados como poco nobles, pintura kitsch por ejemplo (N. de la T.). 
el campo educativo, entre otros- la cultura ha estado ligada a su profundización, cuando ha sido necesario a su adquisición, pero también a la estabilidad, a la norma, a la jerarquía de los valores y de las obras: un poema de reparto de premios no vale un texto de Baudelaire, ni un eslogan publicitario una máxima de Chamfort (Alain Finkielkraut). ¿Pero la cultura no está ligada también a un pensamiento crítico en la práctica, a la autorreflexión, a la duda, a lo que desde el Renacimiento en Europa sabe volver a poner en entredicho las tradiciones y las autoridades? Un transcultural que favorece el regreso crítico sobre la maneras de hacer y de pensar, sobre las instituciones y las obras, debe a la vez librarse de la adoración confitada de las grandes obras, pero también del relativismo estético que ha invadido los medios, la didáctica del FLE ${ }^{2}$ incluida, especialmente cuando ésta privilegia los documentos auténticos. Otra $\mathrm{DLC}^{3}$ debería promover una cultura cultivada transcultural renovada, la de las creaciones reflexivas y buscadas, la de los seres y las obras que atraviesan y transforman las naciones, las etnias, las clases sociales y los sujetos humanos. La DLC tiene la obligación de volver a examinar las culturas refinadas, ya sea que vengan de arriba -la cultura creativa elitista de las grandes novelas, de la gran música, del cine de autor-, o de abajo -la cultura creativa popular de las canciones, de los chistes, de los proverbios o la de lo cotidiano, de la diversión festiva o comercial-, con el fin de hacerlas dialogar (cooperar y enfrentarse) entre ellas. Otro medio, la web, "medio de medios", parece ser considerada actualmente como el medio más libre y el más reactivo $\mathrm{y}$, consecuentemente, el más transcultural. Favorece el libre acceso al conocimiento a través de las fronteras de los países, de las disciplinas y de las culturas. Pero aquí, una vez más, la progresión del conocimiento cuantitativo aumenta en detrimento del conocimiento cualitativo. En efecto, es difícil verificar o jerarquizar la información cuando se escribe "www" en google. Sea como sea, cuando se está instalado en la transculturalidad, simultáneamente se está en un principio de expansión, un espacio de encuentros y de pluralismo, pero inevi-

${ }^{2}$ Francés Lengua Extranjera ( $N$. de la $T$.).

${ }^{3}$ Didáctica de las Lenguas-Culturas (N. de la T.). 
tablemente se está también en un espacio de conflicto de valores, ya sean locales, comunitarios o nacionales, a veces con desinstitucionalización, desjerarquización de las obras, desreglamentación del acceso a los códigos. Esto es válido tanto en economía como en arte. Tomaremos como ejemplo la exposición pública de las colecciones llamadas "El Infierno de la Biblioteca Nacional" en Beaubourg, donde se presentaron obras que hasta entonces habían estado escondidas, guardadas en secreto porque eran objeto de escándalo. De esta manera, ya sea que el cambio y la "travesía" sean vistos de manera positiva o negativa, siempre hay más o menos "transgresión" en el TRANS.

\section{El prefijo también puede querer decir "más allá"}

"Trascendente" quiere decir elevarse, con una connotación de superior, de lo sublime. En filosofía, en teología, se dice "transcendentes" de los términos que tienen un significado universal y que, por consiguiente, sobrepasan todas las categorías. En el campo religioso, el término significa el superación de toda experiencia posible para el hombre, únicamente posible para un Dios de una naturaleza radicalmente superior. También podemos considerar que la idea de Dios, ni sobrenatural ni sobrecultural, es una producción cultural entre otras y que es necesario que luchemos para lo que Michel Onfray denomina con el término de "trascendencia inmanente", una ética temporal inmanente que concierne a todos los humanos. Es este sentido de la agrupación sobre un fondo humano común el que queremos darle a lo transcultural, a fin de rechazar el diferencialismo étnico o sexista, que reduce a cada uno a su territorio cultural o a su supuesto determinismo biológico. En este contexto, desde este momento entendemos la tentativa en el campo jurídico de poner en su lugar a nivel mundial una jurisdicción "transcultural". La "Corte Internacional de Justicia" (puesta en tela de juicio por los USA debido a una ingerencia) tiene como meta proteger los derechos fundamentales. Deslocalizándose, esta Corte internacional apuesta por una justicia fundadora, justicia que quiere luchar contra la impunidad de las masacres contra los civiles y que está comprometida con hacer que disminuyan 
los crímenes contra la Humanidad. Sin embargo, esta Corte tropieza con un problema: ¿cómo asimilar los valores universales teniendo en cuenta la diversidad de las culturas jurídicas nacionales? Es evidente la tensión entre los valores de los derechos del hombre que se han vuelto universales y los valores locales particulares. Pensamos en ciertos países islámicos que practican ese derecho arcaico que es la sharia, donde Dios es el único soberano legista (Tariq Ramadán). Ese Islam, fuente de referencia ofensiva y defensiva de identidades crea debate, con razón, en nuestras sociedades modernas. Entre relativismo cultural y universalismo, el posicionamiento transcultural no es un intervalo, cada uno presentando vertientes negativas y positivas según el lugar de enunciación. Se trata de una cuestión donde se juega el hecho de que los valores de los derechos del hombre están "más allá de este mundo" y cuyo proceso de valorización necesariamente es, a la vez, "conflictivo" y cooperativo.

\section{Lo transcultural de travesía, de transgresión y de transformación: un enfoque discutible pero que merece ser discutido}

140 El pensamiento diferencialista y sus relaciones paradójicas con el universalismo

No siempre es fácil luchar contra el racismo cuando esta lucha se hace en nombre de un ideal y en nombre de principios universales por reconstruir. Los aspectos paradójicos no faltan, especialmente cuando racismo/xenofobia/etnicismo/sexismo se manifiestan por medio de un antirracismo de geometría variable, que sólo concierne, por turnos, a los árabes, a los judíos o a los negros, excluyendo a los demás. Otra paradoja: el pensamiento diferencialista y comunitarista se basa en un principio pretendidamente universal, a saber: la no reducción de las diferencias en la especie humana, ya sean culturales o biológicas. Aquí, el efecto de este "racismo sin raza", como lo llama P. A. Taguief, es el de bloquear a los sujetos humanos en su "origen", en la identidad que los dominantes de su grupo cultural les impusieron y de impedirles construirse su identidad 
a partir de una relación reflexiva, instruida (cultivada) con las sociedades de ayer y de hoy. Esencialista y conservador-reaccionario, el pensamiento diferencialista y comunitarista intimida a los educadores, invitándolos a renunciar a todo horizonte universalista. ¿Libertad, igualdad, fraternidad, laicidad? ¡Sólo son ficciones inútiles, léase dañinas! Desde entonces, las autoridades políticas e ideológicas de cada sociedad son libres de celebrar tanto la ideología de la competición y de los cálculos egoístas (ultra liberalismo), como la del respeto intimidado de algún "gran libro" considerado como incriticable (la Torah, la Biblia, el Corán). ¿No es un derecho a la indiferencia el que de esta manera se opone al derecho de ingerencia, como es el caso por ejemplo para el TPI o los Juegos Olímpicos? ¿Sobre este principio de neutralidad, de "realidad", adaptado a las situaciones concretas, debe fundarse un proyecto educativo que se supone "eficaz" o "funcional”? ¿Sobre este fondo de "realismo pragmático" y comercial podemos hablar de "cultura" en DLC? ¿La DLC debe oscilar entre las culturas de los grupos sociales y las culturas comerciales, debe romper con la dinámica de la cultura humanista hecha de mezclas, de confrontaciones entre culturas? Al abandonar la noción de "civilización", con su atmósfera clásica colonial, para entregarse a las culturas tradicionales y comerciales, ¿no fue de mal en peor la DLC? ¿Debe ella renunciar a una política de emancipación o, al contrario, luchar contra el desmenuzamiento de los valores y preconizar un universalismo hacia el cual deberíamos ir todos?

\section{El relativismo cultural y el pensamiento no igualitario}

La noción de "transcultural" supone no sólo la comunicación de una cultura a la otra, sino también la tensión hacia un más allá, un más allá de las pertenencias religiosas y de las herencias culturales restrictivas, cualquiera que sean las representaciones identitarias. Lo transcultural es lo socio histórico que se emancipa de ciertos conceptos racistas franceses; no tenemos memoria corta y nos acordamos de que el colonialismo francés, en Argelia, dividió a las poblaciones, cultivando la segmentación segregativa entre las identidades. En efecto, el Estado "republi- 
cano" colonialista instauró estatus no iguales para los árabe-parlantes o berebero parlantes, lo que violaba los principios humanista e igualitarios republicanos. Señalemos que, al contrario de lo transcultural, es lo socio histórico lo que emancipa; emancipa del etnologismo conservador, de un cierto etnologismo esencialista que hace de sus observatorios y de sus análisis etnológicos destinos irreversibles, por no decir eternos. Es este etnologismo que domina lo intercultural políticamente correcto del laissez faire la familia el que puede ser, a veces, una cultura de opresión; y es una forma vecina de esta ideología la que anima lo intercultural ultra-liberal, el laissez faire la comunidad o la empresa con sus culturas de explotación. Por ejemplo, en 2008 se ignoró, en nombre de lo intercultural, la explotación de niños, mientras que la Europa social se construyó al precio de largas luchas que terminaron por obligar a los patrones a ya no explotar a los niños en las minas y en las fábricas. Luchas cuyo resultado, lo sabemos, no se ha alcanzado definitivamente. Tomaremos como ejemplo la puesta en duda de la laicidad en Francia. Uno se puede inquietar seriamente con las edificantes palabras de un Presidente de la República, o incluso con la posibilidad para los universitarios católicos de validar sus diplomas al mismo título que la Universidad francesa. Según nosotros, es urgente regresar a la laicidad a la

142 francesa, la que quiere liberarse de los dogmas, la que se refiere a un contexto laico que puede tener autoridad en las instituciones (familia, escuela...) y sus representantes (incluidos los hombres políticos) y que al final hace, y antes que todo, la pregunta fundamental de la naturaleza del vínculo social. La laicidad ha podido afirmarse cuando la dignidad ética y moral del político ha podido permitir pertenencias múltiples y liberar al individuo ciudadano de la influencia de la "tribu", ya sea ésta tradicional y religiosa (Régis Debray) o, bajo una forma postmoderna y plural, las tribus consumistas que celebran el marketing y la publicidad, para las cuales el efecto alienante del grupo, de pertenencia de una categoría, no es menos grande. La laicidad ha pensado en términos de principios, de valores y de ideales a realizar, y no en términos de dogmas a respetar, ni de realismo y de pragmatismo sometidos a la ley de los más fuertes y de los más ricos. La laicidad es primero eso que supimos franquear en el pasado, el fanatismo religioso y el 
reconocimiento de un Absoluto para toda vida humana. No es una opinión, una ideología totalitaria que actúa como una religión; es un principio y una institución de encuentros, de carácter mixto, de intercambios consensuados y conflictivos. El dogma es el "laicismo" que excluye toda expresión de las creencias religiosas en el debate público y que impide al mismo tiempo el examen contradictorio de las opiniones (el laicismo es anti-laico). La laicidad es una armazón conceptual, un espacio racional (no totalitario) que permite la expresión de todas las opiniones en el marco del respeto de la ley y que, por consiguiente, está en la obligación de denunciar ciertos particularismos culturales inaceptables: la escisión, la lapidación, el delito de infidelidad... y en otro plano, el fascismo, el totalitarismo.

Lo transcultural: un más allá necesariamente conflictivo para sociedades "más" humanas que se apoyan en valores universalizables; la pasión razonada de la libertad y de la igualdad en su interdependencia

La globalización nos ha hecho comprender que, de hoy en adelante, hay una comunidad de destino para el conjunto de los seres humanos: para lo bueno la justicia social, o para lo malo la guerra de todos contra todos y el reino del individualismo egocéntrico. ¿Globalización “turbocapitalista" al servicio de los intereses y los beneficios inmediatos de algunos, o globalización humanista mirando hacia los intereses colectivos de las poblaciones de hoy o de mañana? Aunque nuestra definición de lo transcultural nos opone al multiculturalismo, no buscamos ni negar ni romper las solidaridades nacionales o culturales, sino más bien incluirlas o sobrepasarlas. Ante la presión de los oscurantismos (en los USA como en el mundo árabe-musulmán; en Europa y en África como en América latina o en China), pensamos que las instituciones nacionales (los sistemas educativos forman parte) e internacionales deberían proteger y garantizar los derechos de los individuos a pensar libremente, deberían favorecer la expresión y la discusión de las opiniones y de las creencias sobre la base de principios y de valores "universalizables". 
CHANTAL FORESTAL

La libertad de pensamiento: no hay arte sin transgresión, no hay pensamiento sin provocación

El pensamiento no sólo son raíces, también son flores y frutos. En el pasado, el mundo musulmán conoció una época de apertura económica y cultural donde los letrados árabes o persas intercambiaban directa o indirectamente con los letrados de la India, de China o de Europa. Históricamente, en Francia, a partir de los Derechos del hombre, empieza el reconocimiento de las libertades fundamentales, especialmente la libertad de pensamiento conquistada contra la Iglesia y otras fuerzas políticas. Desde el siglo XIX hasta nuestros días, es una historia más que caótica, que pasa por la escuela laica llamada "escuela de los sin-dios" y por el derecho de poner carteles y de asociación. Hay que defender este núcleo de universalismo tanto en Francia como en el interior de este espacio de intercambio que en teoría es la francofonía. Tomaremos como ejemplo un país como Túnez, donde todavía existen ciertas adquisiciones del burguibismo en materia de educación y de los derechos de la mujer, pero en el cual la libertad de expresión es deficitaria. Sucede lo mismo en Marruecos, donde ser pagano es un delito... En filosofía como en ciencias, en literatura como en las artes

144 plásticas, la creatividad es indisociable de la libertad de pensamiento, de imaginar, ella misma indisociable de la transgresión y de la provocación: de Madame Bovary a La religiosa de Jacques Rivette, de los dibujos de L'Assiette au Beurre (El plato de mantequilla) a los de Charlie$\mathrm{Hebdo}^{4}$ pasando por El desertor de Boris Vian. Es verdad que "todo se complica". Por el moralismo y la invocación al respeto de las culturas (aunque, hasta la saciedad, no respeten los derechos de sus miembros), los líderes vuelven a poner en duda la libertad de expresión de las sociedades con tendencia democrática. El derecho a chocar, a poner a pensar (a través del humor, de la caricatura, de la sátira), aliado con el derecho de responder y de discutir, debe hoy ser defendido, ilustrado y reforzado. De esta manera, la noción de "humor exolingüe", citada por G. V. Margin (2001 y 2002), muestra que la risa de los humoristas

${ }^{4}$ Revista francesa, ilustrada y satírica. Sus publicaciones han sido muy controversiales, como el caso de las caricaturas de Mahoma publicadas en el 2006 ( N. de la T.). 
-como Semain, Boujenah, Tazairt, Djamel, Eric y Ramzy- es exolingüe en la medida en la que las divergencias entre los repertorios franceses y árabes construyen el significado cómico de los sketches. Por los temas recurrentes sobre la escoba, la aduana, el control de identidad, los conflictos de generaciones, estos humoristas son transmisores culturales que colocan una estrategia identitaria mediante la risa transgresiva. Habría que añadir a Devos, este "charlatán sideral", que ha sabido hacer malabarismos con las palabras, el abanico de sus significados, el sentido y el no-sentido, los contrasentidos hasta la provocación. Todavía hoy, las libertades políticas republicanas, a la vez liberales y sociales, individualistas y solidarias, están amenazadas por minorías potentes o autoridades institucionales que hablan en nombre de la mayoría silenciosa. En sus actividades públicas y profesionales, periodistas, artistas pero también profesores, practican la censura o la autocensura bajo pena de represalias económicas, judiciales o físicas. Los jóvenes en prácticas o los profesores precarizados son, a su vez, invitados a "auto normalizarse".

\section{Lo transcultural: una conducta específica en didáctica que también merece ser debatida}

El relativismo cultural prosperó a partir de la idea de que las culturas, las naciones, lo pueblos están definidos por espacios-tiempos homogéneos. Ese relativismo es un engaño en situaciones de desplazamiento, donde el individuo se encuentra ligado afectiva e ideológicamente a varios grupos, redes y territorios, y cuando debe desarrollar capacidades adaptativas. Ese relativismo se muestra indefendible en una época en la cual los proselitistas religiosos (budistas, cristianos, hindúes, judíos o musulmanes) quieren remplazar el principio racional de una relación crítica y deliberadora en el mundo por una relación de sumisión a una tradición y por la policía de pensamiento. Aquí hay un desafío para la instrucción y la educación emancipadoras, que deben respetar esas ideologías, pero dándolas a conocer. 
La dimensión transcultural promueve una cultura abierta a los derechos del hombre, una disposición a compartir lo humano

Esta intención de un horizonte de universalidad fue la idea principal de los filósofos llamados de las Luces, de los cuales hay que retomar y prolongar el programa luchando contra la idea de incomunicabilidad de los hombres y de las culturas. Tenemos que franquear los límites del multiculturalismo y del interculturalismo, sobre todo cuando nos limitan en la celebración de la diferencia, de las singularidades distintas, al respeto intimidado de las herencias culturales y de las formas de pensamiento y, a final de cuentas, cuando olvidan los rasgos comunes de todos los seres humanos: en particular su disposición a abandonar las rutinas y las protecciones, desde que prueban un mayor bienestar hecho de seguridad, de cooperación, pero también de libertad y de creación. Voltaire no debería ser el último escritor feliz en creer en el universalismo. Los foros sociales, las asociaciones, son muchas instancias de este universal que defienden el bien común, por consiguiente, lo contrario de una yuxtaposición de las diferencias. Los sistemas educativos de enseñanzaaprendizaje de las lenguas deben volverse instancias que también alberguen este universalismo.

La dimensión transcultural implica un proyecto de emancipación, una "humanística" para progresar (Albert Jacquard)

El curso de lengua-cultura extranjera puede ser un lugar de instrucción del ciudadano capaz de tener espíritu crítico, capaz de juzgar el bien y el mal o, en términos menos metafísicos, "bueno" o "malo". Se trata de crear un espacio de encuentro, de intercambios y de confrontación de las visiones culturales y de las opiniones, con el fin de abrir posibilidades que permitan, a los individuos ligados o afiliados a grupos culturales, convertirse en sujetos por medio de sus desacuerdos y de sus acuerdos pensados y discutidos. Entendemos que desde esta perspectiva, los enfoques llamados, al otro lado del Atlántico, "humanistas", donde lo mejor del enfoque comunicativo nos parece que forma parte, no ha dicho su última 
palabra en DLC. Mirando hacia la acción en sociedad, la versión transcultural de la metodología humanista deberá explotar las adquisiciones de la perspectiva de acción del Marco Común Europeo de referencia (task-based learning) rebasando, sin embargo, sus características heredadas de la cultura de empresa dominante: hiperfuncional, tecnicista, mecanista. Hoy como ayer, al salir del behavorismo aplicado, debemos esforzarnos por volver a humanizar la didáctica de las lenguas-culturas, o al menos, de no someternos a la deshumanización que avanza bajo pretexto de "profesionalismo". En vez formar alumnos operacionales, la didáctica de las lenguas debería desarrollarse como un componente ético, por el cual la ciudadanía estaría en el centro de la formación de la comunicación y de la acción colectiva (Maryline Langlois). Desde ese momento, se impone una condición previa: debemos luchar contra el agnosticismo metodológico que consiste en observar una neutralidad condescendiente o de no intervención con respecto a ideas y a comportamientos de actores de la enseñanza-aprendizaje, y que finge creer que los saberes y las maneras de ser transmitidos no tienen ninguna relación con la sociedad, el mundo exterior y sus valores (Maurice Sachot); mientras que un dispositivo burocrático ganado por "la evaluación certificadora", conduce a los profesores y a los alumnos a dispensarse de reflexionar sobre el bien fundado de ciertos objetivos. Ese reduccionismo fatal, que determina esencialmente la cognición y los comportamientos observables y que ignora los deseos, los afectos y la imaginación de los sujetos humanos, incita a renunciar a las finalidades emancipadoras de la DLC. Si la educación de las lenguasculturas ayuda a vivir mejor juntos, a sublimar los miedos y los odios y a sobrepasar los prejuicios y las inculturas, no puede no tomar en cuenta la transmisión de valores que no resuman la formación en lenguasculturas en una formación profesional, ni a una estructuración ajena, respondiendo a las demandas inmediatas de los empleadores. Todo esto implica una reflexión a nivel meta comunicativo (Jacques Demorgon), lo que supone un trabajo voluntarista, el de los educadores, y en particular el de los especialistas en didáctica. En esta perspectiva, el componente transcultural no sólo puede completar, sino también renovar los diferentes procesos de enseñanza-aprendizaje de la cultura. Un verda- 
dero proyecto educativo es necesariamente filosófico: debe permitir al alumno-ciudadano, el cual ha podido informarse y discutir para juzgar, construir mediante varias lenguas-culturas su concepto del bien o bueno, del mal o malo. Para una buena vida, o al menos, una mejor vida en común. En relación con una gestión multicultural, la gestión transcultural reconoce las diversidades externas e internas entre y en las poblaciones-culturas, en cada individuo, pero no se cierra. En efecto, lucha contra las fosilizaciones esencialistas de diversos etnicismos: comunitarismos con fundamentos religiosos y/o racial, occidentalismo separatista del "choque de las civilizaciones".

En relación con una gestión multicultural, la gestión transcultural no se reduce a un principio puramente "adaptativo", a saber, la capacidad de apuntar hacia una simple investigación en una sociedad extranjera. Como lo recuerda Gilles Verbunt, la apertura cultural no es necesariamente positiva si se hace bajo el modo de la sumisión a normas-valores regresivos, como los que ponen en duda un valor, un ideal de igualdad entre el hombre y la mujer. Ciertamente, el intercambio entre culturas debería corresponder a un proyecto elaborado en común para vivir juntos, pero también a un "más cultural". No se trata de que, aceptando ciertas normas-valores "de otro lugar", se vuelva a valores similares a aquellos cuyas luchas históricas de "aquí" tomaron siglos en emanciparse (véase las de Arnolfo y de Tartufo). Si lo intelectual implica una adaptación, lo transcultural va más allá e implica una transformación. Regresión o progreso social, aquí también, hay que escoger y construir.

Asimismo, si es co-cultural (C. Puren) la DLC transcultural no debe volverse una "co-neutralización", una neutralización mutua de las ideas y de los discursos que enojan. Esquivando la cuestión de las finalidades, la visión llamada "pragmática" no responde suficientemente a la necesidad de luchar contra los horrores y los errores que acentúan la historia pasada y presente de la humanidad, y que siempre nos amenaza. La dimensión transcultural a la que aspiramos, a la vez ética y política, no puede limitarse a metas y objetivos utilitarios, subordinados a las urgencias de la supervivencia del mundo. Movimiento de transformación mutua, el proceso que defendemos aspira a reunir 
las condiciones de posibilidad para experiencias de co-creación emancipadora. Instituiría normas de comunicación y de acciones productoras que conducirían a los participantes a protegerse mutuamente de los autoritarismos venidos de arriba o de abajo, venidos de aquí o de otro lugar.

El acercamiento sistemático y sus implicaciones en didáctica de las lenguas: ¿una presencia del modelo tranquilizadora o inquietante?

Todos los aspectos abordados anteriormente exigen una reflexión epistemológica. En artículos anteriores, hemos tenido la ocasión de evocar el acercamiento sistemático de los trabajos del Consejo de Europa y sus implicaciones en DLE. ${ }^{5}$ Observaremos que este acercamiento rechaza reconocer sus vínculos con la teoría de Marx, aunque haga alusión a las nociones de relaciones de fuerzas y de dinámica que lo acercan al materialismo histórico y dialéctico. Sin embargo, lo que para Marx se presenta como un método que permite analizar una realidad para pesar sobre ella y transformarla fundamentalmente, para el enfoque sistémico sólo es una herramienta destinada, en el mejor de los casos, a habilitar el sistema en su lugar o, en el peor, a "reformarlo" en el sentido en que hoy se habla de reformas necesarias y dolorosas (para los más débiles y perdedores). ¿En qué se convierte el proyecto, llamado "multilingüe", de la Comisión Cultural del Consejo de Europa en Francia, como en otros lugares, cuando se reduce el presupuesto de la cultura, cuando se despide a los colegas en los institutos, cuando se fragiliza a los actores que son los profesores cuyo trabajo se minimiza y el salario se ridiculiza? ¿En qué se convierten las políticas multilingües cuando todas se reducen más o menos al monolingüismo de la enseñanza del inglés o cuando no pueden proyectarse más que en el marco de la privatización de la enseñanza de lenguas (véase las frondistiria en Grecia)? Es uno de los límites del proceso sistémico de los expertos

${ }^{5}$ Didáctica Lengua Extranjera (N. de la T.). 
CHANTAL FORESTAL

que anuncia la no ingerencia en los sistemas educativos nacionales pero que, de esta manera, abandona o desvía las proposiciones de los formadores, de los investigadores de ese mismo Consejo de expertos, e impide inventar soluciones "meta" que saldrían de los límites del marco ultraliberal. ¿La perspectiva accional del CECR privilegia actividades de adaptación o actividades de transformación? Reproducir o transformar el sistema socio-económico-cultural globralizado, hay que escoger...

\section{De una postura profesional ética a una práctica pedagógica}

\section{La tecnología o el espíritu crítico}

Muy a menudo, nuestra disciplina se encierra en una tecnicidad en la cual la metodología se pone bajo la tutela de la evaluación. Cada vez más tiende a minimizar los contenidos culturales o ideológicos, de la misma forma que adquirir métodos o estrategias (ya sea que las conductas sean meta, inter o co-culturales), enseñar-aprender un idioma es aprender a construir y a compartir sentido (Robert Galisson). En un mundo ideológico gobernado por la informatización de masa, más que nunca es necesario formar los espíritus para que vigilen frente a la opinión común; aprender a deliberar para juzgar el bien y el mal; y esto desde la infancia, siguiendo los consejos de Alain, quien no quería un gurú, sino alguien que le ayudara a despertar. ${ }^{6}$

Frecuentemente, el aspecto técnico y operacional tiende a dominar sobre el contenido existencial. Uno se pregunta si la didáctica de las lenguas-culturas no se convertiría entonces en una especie de "management aplicado". En este aspecto, la evolución de la investigación en nuestro sector es muy reveladora. En el $\mathrm{CNU}^{7}$ hemos asistido a una proliferación de expedientes en FLE sobre la evaluación, sobre el papel de las

\footnotetext{
${ }^{6}$ Véase el artículo de Yannick Lefranc, Discutir libremente en FLE-FLS: un dispositivo transcultural por lo tanto político, en ELA, núm. 152, 2008.

${ }^{7}$ Consejo Nacional de Universidades ( $N$. de la $T$.).
} 
herramientas multimedia y de los documentos técnicos. De esta manera, varios trabajos sobre la mejora de la comprensión se preocupan de la interación práctica de los CD Rom, de las páginas de internet, de la hipertextualidad, de la interactividad, de la multimodalidad. Pero no se habla nada de "Cultura" con "C" mayúscula. Se debate muy poco sobre el sentido o los efectos de los sentidos de los mensajes. No preocupa para nada educar preventivamente a los alumnos en una lectura crítica de las páginas web oscurantistas (racistas, integristas, cientistas u ovnistas), ni al análisis saludable de las inculturas, de los populismos o de los elitismos. Se habla de esterotipos, pero no de los medios para detectarlos y aún menos para sobrepasarlos o cuestionarlos. Y en el plano de la cultura, la oferta está del lado del continente e insuficientemente del lado del contenido.

La axiología y la ética: dimensiones arriesgadas, pero caminos obligados en DLC

Finalmente, muy a menudo, ciertos contenidos son considerados de entrada como demasiado arriesgados. ¿Para cuándo un manual de FLE que hable de las cárceles francesas, de lo nuclear y de la venta de armas, de la agricultura industrial, de nuestros lugares de memoria y de luchas sociales, de las sumisiones y de las resistencias a las opresiones, de los procesos de las mujeres en el Magreb, de la acogida de inmigrantes y del problema de los inmigrantes ilegales, etc.? ¿Y quién, en estos temas, confrontaría al FLE con las lenguas-culturas alemana, árabe o española, china? ¿Y, hablando de laicidad, quién haría un paralelismo entre la laicidad turca y el régimen secular estado-unión o los "acomodamientos" de la laicidad quebequés?

\section{Algunas pistas transculturales}

La perspectiva, a la vez ética y práctica, debería apoyarse en un componente trancultural hecho, ya lo hemos dicho, de travesía/transgresión/ 
CHANTAL FORESTAL

transformación de las culturas. A partir de ahora, con la globalización, el reto al que se enfrenta todo sistema educativo es el de asumir los conflictos nacidos de la multiplicidad de los valores y de las representaciones. "Reprimir el conflicto sólo puede favorecer, a más o menos largo plazo, la violencia generalizada". Para hacer frente a las situaciones de desacuerdos ideológicos (morales y políticos) entre alumnos de diferentes culturas, la conducta consistiría en someter los propósitos a reformulaciones cruzadas y mutuas; después, a una discusión argumentada en la lengua materna o en la lengua determinada por medio de la reformulación en L2, del code-switching y de la traducción. Para acostumbrar a los alumnos -y a los profesores- a distanciarse de sus opiniones espontáneas, y para entrenarlos a justificar o a reformular su argumentación (habilidad discursiva), se escogerían varios documentos con opiniones contradictorias, susceptibles de comprometer a los lectores y de conducirlos a una reflexión que integre la complejidad de los fenómenos y la pluralidad de los puntos de vista. Se podría, a tal efecto, sacar partido de ciertos trabajos, tales como: los trabajos del CLEMI (Centro de Conexión de la Enseñanza y de los Medios de Información) sobre los medios; el CD educativo sobre la declaración de los derechos del hombre, producido por RFI y el CAVILHAM de Vichy; el proyecto PRAX

152 (Prevenir el Racismo, el Antisemitismo y la Xenofobia) de Mathieu Valette y François Ratier, que está en Internet y tiene como objetivo desarrollar una pedagogía crítica de la retórica racista, creando una herramienta transversal; ${ }^{8}$ los trabajos de David Ravet, quien no tiene miedo de presentar una didáctica de los textos comprometidos entre el capitalismo americano de los años 20 contra el colonialismo francés en África de los años 30. Este autor promueve una pedagogía del compromiso por medio de una metodología transartística, que confronta textos literarios, cine, carteles colonialistas y fotografías; los trabajos sobre el RAP. Esos trabajos subrayan el callejón sin salida de las posturas secundarias y victimistas. Algunos textos de RAP son violentos, pero no todos. Existe un RAP que denuncia la violencia conyugal, el acoso en el trabajo, que enseña el respeto (Caroline Fourest); los acercamientos no convencio-

${ }^{8}$ Véase Les Langues Modernes, abril-mayo, 2006. [Revista de la Asociación de Profesores de Lenguas Vivas (N. de la T.)]. 
nales que obligan a reconsiderar varios aspectos de la relación profesor-alumno y que invitan a proporcionar fuertes soportes existenciales a nivel de contenidos de aprendizaje, que se inscriben en una larga tradición humanista; el expediente propuesto por la página web "francparler.org", que tiene como finalidad desarrollar una conciencia ciudadana al introducir lo político en una clase de lengua. El expendiente comprende fichas pedagógicas que conciernen a la militancia, el discurso de los hombres políticos, los entresijos de las elecciones. Pero, como lo decía Frederik Dark "el hombre desciende del sueño así como del simio". También se puede tratar de aprender a soñar juntos, a confrontar nuestros imaginarios, ya sea que estén del lado de lo maravilloso, de los mitos fundadores, de la religión, de la creación artística, de la literatura, incluidos el humor, la parodia y la caricatura. ${ }^{9}$

\section{Conclusión}

Si lo intercultural a menudo remite principalemente a las relaciones entre individuos, lo transcultural moviliza lo colectivo más allá de cada individuo o más allá de las relaciones entre individuos. Para los profesores implica adoptar en nuestro dominio una postura profesional ética. Más que otros, los profesores-especialistas en didáctica de las lenguas-culturas son "pasadores" (R. Galisson). Más que otros, los especialistas en didáctica no deben contentarse con "una disciplina que se baste a sí misma, cortada de la sociedad, de las instituciones y de los hombres" (Maurice Sachot). Más que otros, deben favorecer una cierta "imprudencia disciplinaria" y luchas contra una pseudo neutralidad con respecto a los contenidos, una dimisión sobre el plano educativo. El contexto histórico y social ya no permiten, en la enseñanza de las lenguas extranjeras, evitar la cuestión de las finalidades que conciernen a los contenidos y a los procesos pedagógicos. La didáctica de las lenguas tiene el derecho y el deber de hacerse la pregunta esencial de

${ }^{9}$ Véase el artículo de Gérard Vincent Martin, El humor en clase de lengua: de lo exolingüe a los translingüe, en ELA, núm. 152, 2008. 
nuestra supervivencia y de nuestro porvenir en tanto que especie humana. Incluso si no tenemos la certeza, incluso si no podemos decidir sobre lo que favorecería la llegada de una nueva moral, debemos apostar sobre un universal humanista por construir. Y hacer moral sin hacer la moral. Transversal en los procesos inter, meta y co-culturales, el proceso transcultural de la DLC tiene, en efecto, una dimensión filosófica, es decir, a la vez ética y política, que participa de la búsqueda de una "buena vida" para cada uno y para la comunidad de los hombres. Si se libera de los reduccionismos económicos y éticos, la didáctica de las lenguas-culturas hará vivir a sujetos parlantes de todos los países experiencias dialógicas, donde crearán juntos discursos y obras, a partir de sus singularidades socio-históricas, de sus acuerdos y de sus desacuerdos. Vueltos hacia una praxis que va bastante más allá del "pragmatismo" en boga, la DLC no debería contentarse con poner el contacto intercultural como un objetivo esencial, que debiera, él solo, permitir un cambio de mentalidades y de relaciones (Lipiansky). Es preferible proponer a los participantes un marco de acción común y de cooperación, apoyándose en motivaciones profundas (profesionales, culturales, científicas, existenciales), de las que se abren a todas las dimensiones de lo humano, de la libertad de jugar a la libertad de soñar despierto o de crear utilizando, eventualmente, acercamientos no convencionales. Apostemos a que esas experiencias colectivas de aprendizaje creativo no suspenderán en los alumnos ni antagonismos de intereses ni las intimidades. Pero las clases de lenguas-culturas los representarán, pondrán en escena (y por lo tanto a distancia) como relaciones entre personas concientizadas y no como oposiciones entre portavoz de tal o tal etnocultura. A nivel de la práctica, es conveniente llevar a cabo un marco pedagógico que permita, a la vez, preservar su dignidad ("su aspecto"), de sentirse seguro y de ser reconocido. En lo que concierne a los profesores-formadores, la formación debería aprender a distinguir, como es el caso de los educadores sociales: el distanciamiento, la implicación, el compromiso. De esta manera, después de Jacques Ardoino, Yann Legoff recuerda precisamente que tomar distancia no es necesariamente permanecer indiferente y no estar implicado. El compromiso "en tanto que intervención consciente [...] viene a decir la manera en la cual el educador 
sabe cómo actuar, hace referencia a sus valores, expresa sus posturas. Puede hacer un reposicionamiento seguido a una toma de distancia”. Se puede lamentar, desde entonces, que en nuestro campo no se hizo lugar a una reflexión colectiva que reagruparía a todos los actores de la DLC deseosos de crear "un comité de las Lenguas-Culturas", y permitiría profundizar la reflexión sobre los contenidos éticos y deontológicos.

Hemos renunciado a la noción de "competencia ética". Por una parte, porque el término de competencia remite al vocabulario de la gestión de una empresa (el "management"); por otra, porque la ética no puede ser objeto de una competencia. El bien y lo bueno o, al menos, lo "suficientemente bueno" (Winnicott) son constatables, sentidos y verificables pero no medibles. Lo vivido siempre sobrepasará a la evaluación, al menos cuando ésta se reduce a su dimensión técnica y certificativa. Definitivamente, sería bueno concluir con una cita de Paul Ricoeur: "Llamemos intención ética a la intención de la buena vida con y para el prójimo en instituciones justas". 
CITAM Derechos Reservados.

La reproducción total o parcial de este artículo se podrá hacer si el ITAM otorga la autorización previamente por escrito. 


\section{DOSSIER}

El jueves 16 de octubre del 2008, cuatro personas se dieron cita para rendir un homenaje a su amigo común, de la forma en que probablemente más le hubiera gustado: presentando un libro de su autoría. Los textos que escribió durante veinte largos años (1988-2008) en diversas publicaciones, son ensayos, notas y reseñas sobre filosofía, sociología, política, cine, educación, amistad, cuidadosamente compilados y ordenados en el volumen Textos atorrantes (México, 2008, Ediciones Coyoacán, 385 pp.). Éste es el testimonio de lo que entonces dijeron sus compañeros de vida.

Alberto Sauret Botteri nació en Argentina, en la provincia de Entre Ríos, departamento de Victoria. Fue Licenciado en Comunicación Humana por la Universidad del Salvador, Buenos Aires, y Doctor en Filosofía por la Universidad Iberoamericana, Ciudad de México. Profesor del Departamento Académico de Estudios Generales del ITAM, fue también Jefe de Redacción de nuestra revista Estudios. Filosofia. Historia. Letras, desde el número 12 (primavera de 1988) hasta el 68 (primavera del 2004): años de arduo y meticuloso trabajo. También nosotros le rendimos un sentido homenaje.

Requiescat in pacem. 
CITAM Derechos Reservados.

La reproducción total o parcial de este artículo se podrá hacer si el ITAM otorga la autorización previamente por escrito. 